\title{
Comparison of Aerobic and Anaerobic Capacities among Smoker and Non-smoker Male Collegiate Population
}

\author{
Kalpana Zutshi', Mahvish Oaiser', Nahid Khan ${ }^{3}$
}

${ }^{1}$ Associate Professor, ${ }^{3}$ Assistant Professor, Department of Rehabilitation Sciences, SNSAH, Jamia Hamdard, New Delhi, India. ${ }^{2}$ Physiotherapist at Ekbalpur Nursing Home 9, Ibrahim Rd, Ekbalpur, Khidirpur, Kolkata, West Bengal, India.

DOI: https://doi.org/10.24321/0019.5138.202120

\section{I $\quad \mathbf{N} \quad \mathbf{F} \quad \mathbf{O}$}

\section{Corresponding Author:}

Mahvish Qaiser, Physiotherapist at Ekbalpur Nursing Home 9, Ibrahim Rd, Ekbalpur, Khidirpur, Kolkata, West Bengal, India.

E-mail Id:

mahvishqaiser@gmail.com

Orcid Id:

https://orcid.org/0000-0002-9781-825X

How to cite this article:

Zutshi K, Qaiser M, Khan N. Comparison of Aerobic and Anaerobic Capacities among Smoker and Non-smoker Male Collegiate Population. J Commun Dis. 2021; 53(2): 14-17.

Date of Submission: 2021-01-22

Date of Acceptance: 2021-06-23

\section{$\begin{array}{llllllll}\mathbf{A} & \mathbf{B} & \mathbf{S} & \mathbf{T} & \mathbf{R} & \mathbf{A} & \mathbf{C} & \mathbf{T}\end{array}$}

Background: Cigarette smoking is common among the male collegiate population. It causes various negative effects on their body, particularly it affects the lungs. Hence, the aim of this study is to compare the aerobic and anaerobic capacities among the smoker and non-smoker male collegiate population.

Methods: 68 healthy male college students participated in this study. Aerobic capacity was assessed by 3-minute step test. Anaerobic capacity was assessed by 30 -meter sprint fatigue test. T-test was used to compare the data between groups.

Result: Present study reported that smokers had a higher heart rate after performing 3-minute step test. The fatigue index was higher in smokers as compared to non-smokers.

Conclusion: From the present study it can be concluded that cigarette smoking reduces the aerobic and anaerobic capacities of an individual.

Keywords: Smoking, Aerobic capacity, Anaerobic Capacity

\section{Introduction}

Physical ability including aerobic and anaerobic capacities is necessary to perform daily living activities. Aerobic energy system helps in performing long duration activities. Anaerobic energy system provides a burst of energy to sustain short duration high-intensity tasks.

Smoking is defined as the inhalation of the smoke of burning tobacco that may occur occasionally or habitually as a consequence of physical addiction to some chemicals, primarily nicotine. ${ }^{1}$ Smoking prevalence in men and women averages $42 \%$ and $24 \%$ respectively, for developed countries, and $48 \%$ and $7 \%$ respectively, for less developed countries. ${ }^{2}$ There are 26.7 crores tobacco users belonging to the age group of 15 years or more years. 3500 people die daily in India due to tobacco. ${ }^{3}$ Cigarette smoking is a common lifestyle habit among the collegiate population. Previous researches have focused on the prevalence of smoking among secondary school students, graduate students, and adults. Once this population starts smoking, it becomes difficult for them to quit. ${ }^{4,5}$

Cigarette contains harmful substances that affect health. It reduces cardio-respiratory fitness by affecting aerobic and anaerobic capacities. ${ }^{6,7,8}$ As per an Indian Council of 
Medical Research (ICMR) survey conducted in 2017, for the prevention of non-communicable diseases, one should not consume tobacco. ${ }^{9}$ Various pieces of research have been done which check the aerobic capacity of the Indian population in different regions. ${ }^{10,11}$ Shenoy et al. found the relationship between risk factors of cardiovascular disease and aerobic capacity in a study conducted on north Indians. ${ }^{10}$ Research has been done which checks anaerobic capacity in elite power sports players, ${ }^{12}$ but no such study was conducted in India on male collegiate smokers and nonsmokers to compare their aerobic and anaerobic capacities. The present study hypothesised that aerobic capacity and anaerobic capacity are reduced in smokers as compared to non-smokers.

\section{Methods and Materials}

Present study was conducted at Rehabilitation Centre, Jamia Hamdard in New Delhi, India between December to march.

Ethical approval/Informed consent: The study was a crosssectional non-experimental type for which prior consent of participants had been taken after explaining the testing equipment, tests, and study protocol.

A total of 70 subjects were invited to participate in the study. Out of those, 68 subjects had participated.18 to 25 years male collegiate smokers and non-smokers, with the smokers having a history of smoking of minimum of two years were included in the study. Subjects with any cardiovascular, respiratory, musculoskeletal, neurological, psychological disorders were excluded from the study.

Subjects were divided into two groups based on their smoking history. Chronic chain smokers were labelled as group $A$ and non-smoker subjects were labelled as group $B$.

Everyone was instructed to avoid caffeine, alcohol, and heavy meal on the day of testing. A practice test was performed three days before the formal test to familiarise the subjects with the mode and method of testing. It was identical to the formal test. ${ }^{7}$

Warm-up was done before testing to avoid any injury. It included 5 minutes of jogging. YMCA 3-minute step test was performed by using a wooden box of 12 inches. Metronome was set at 96 beats per minute. Subjects were instructed to follow each beat of the metronome. They had followed the cadence of up, up and down, down and continued it for 3-minutes. After three minutes, they sat on a wooden box and their heart rate recovery was measured for one minute by using a pulse oximeter. Pulse oximeter is an appropriate, non-invasive way to measure heart rate either at rest or during and after exercise. ${ }^{8}$ Age-adjusted heart rate standards were given by YMCA. Based on that, we ranked the subjects as excellent, very good, good, poor, and very poor. A rest period of 48 hours was given between 3-minute step test and sprint fatigue test.

Four marking cones were used. Out of which, two were placed at a 30-meter distance which indicated the sprint distance. Two cones were placed on each end at a $10-\mathrm{m}$ distance. Subjects sprinted for $30 \mathrm{~m}$. One stopwatch was used to measure lap and the other recorded the total time. The subjects were allowed to slow down in the 10-meter distance. They performed 10 sprints and the total time was recorded. The fatigue index was then calculated by calculating the average speed of the first three trials and dividing it by the average speed of the last three trials and a value approximately between $75 \%$ and $95 \%$ was obtained. A fatigue index of more than $89 \%$ indicates excellent anaerobic capacity. $80 \%-89 \%$ indicates good anaerobic capacity. $80 \%-84 \%$ indicates average, and below $80 \%$ indicates poor anaerobic capacity. After one week, a formal test was performed.

Analysis was done by using SPSS (Statistical Package for Social Sciences for Windows) software, version 16. T-test was used to find the differences in pre-heart rate (PHR), heart rate recovery (HRR), and fatigue index between smokers and non-smokers.

\section{Results}

A total of 68 subjects went through the testing protocol. All of them were healthy age-matched collegiate. The mean and standard deviation of age and BMI of group A were $22.147 \pm 2.13$ and $20.62 \pm 3.48$, and that of group $B$ were $21.41 \pm 2.07$ and $21.37 \pm 2.74$.

The mean and SD of PHR and heart rate recovery (HRR) were $86.04 \pm 12.89$ and $114.84 \pm 19.98$ respectively. T-test for the difference between mean pre-heart rate and postheart rate revealed that the difference between mean PHR and HRR was statistically significant and the mean levels of heart rate had increased after the test.

T-test for the difference between mean pre-heart rate of smokers and non-smokers revealed that there is a significant difference between the mean PHR of smokers and that of non-smokers. Mean levels of PHR is higher for smokers than that of non-smokers. T-test for the difference between mean heart rate recovery of smokers and non-smokers revealed that there is a significant difference between the mean HRR of smokers and that of non-smokers ( $<<0.05)$. Mean level of HRR is higher for smokers than that of nonsmokers (Table 1 and Figure 1).

The mean and SD of fatigue index of smokers and nonsmokers are $95.29 \pm 28.87$ and $90.50 \pm 9.76$ respectively. T-test showed that fatigue index is higher in smokers with a p-value of 0.36 (Table 1 and Figure 2). 
Table I.Mean, Standard Deviation, T-value and P-value of the Values

\begin{tabular}{|c|c|c|c|c|}
\hline & Group A (Smokers) & Group B (Non-smokers) & t-value & p-value \\
\hline PHR (beats/min) & $93.76 \pm 12.37$ & $78.53 \pm 8.25$ & 5.89 & 0.00 \\
\hline HRR (beats/min) & $128.74 \pm 17.53$ & $100.94 \pm 10.28$ & 7.97 & 0.00 \\
\hline Fatigue index & $95.29 \pm 28.87$ & $90.50 \pm 9.76$ & 0.91 & 0.36 \\
\hline
\end{tabular}

PHR: Pre-heart rate, HRR: Heart rate recovery.

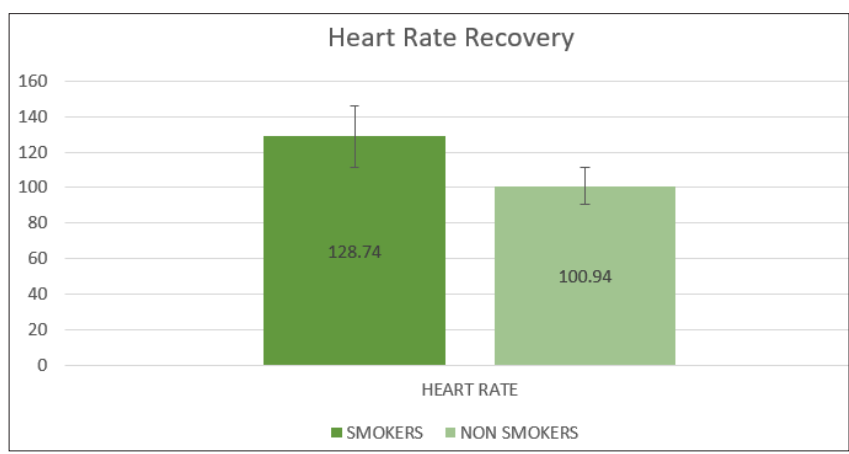

Figure I.Comparison of Heart Rate Recovery between Smokers \& Non-smokers

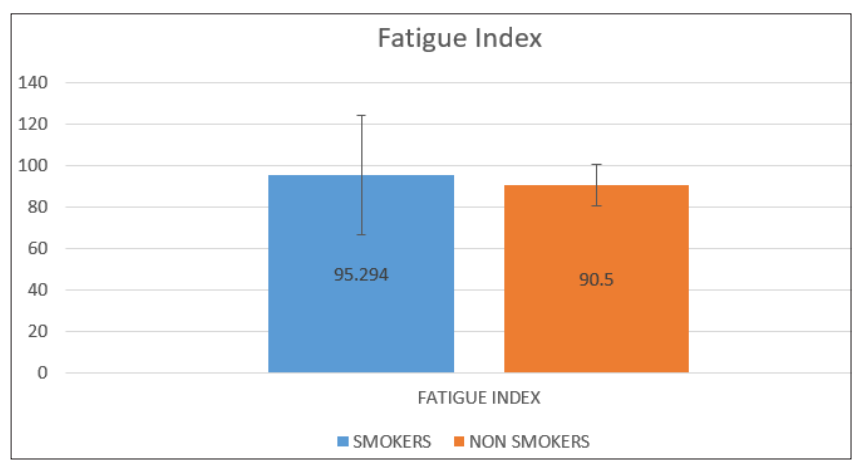

Figure 2.Comparison of Fatigue Index between Smokers and Non-smokers

\section{Discussion}

Aerobic capacity can be assessed by assessing heart rate recovery. Group A (smokers) had higher heart rate recovery and resting heart rate. This is due to smoking which contains tar and nicotine like substances. Many people had started smoking to ease the feeling of stress that comes with depression or anxiety. Smoking reduces the oxygen-binding capacity of haemoglobin in their bodies as a small amount of carbon monoxide binds with haemoglobin..$^{13,14,15,16,17}$ This can reduce the oxygen diffusion capacity in the lungs. These findings are consistent with the findings of lee et al., ${ }^{13} \mathrm{~A}$ higher heart rate can also be due to anxiety, depression, thyrotoxicosis, higher blood pressure, and excessive alcohol consumption.

Fatigue index means the rate at which power declines. Another finding of our research was that we found a higher fatigue index of smokers which shows that they get tired easily while performing anaerobic activities. Sprint exercise uses ATP and PCr as a source of energy but smokers rely upon glycolytic metabolism which ultimately reducing their anaerobic capacity. This is supported by a study conducted by McDonough et al. which states that smoking increases the reliance upon glycolytic metabolism during exercise which contributes to earlier fatigue in smokers as compared to non-smokers who exercise. ${ }^{16}$ Study by Huie et al. concluded that smokers have higher blood lactate concentration and it did not affect the glycolytic metabolic pathway therefore, if the duration of sprints increases while performing the IST, it didn't . However, the effects of smoking on blood lactate concentrations and heart rate during anaerobic exercises are still unclear and require further examination. ${ }^{18}$

It was seen that physical activity helps to maintain normal physiological functioning of the body; therefore, a study can be done in future to compare the effect of smoking between those who are smokers and are actively involved in any sports with those who are not actively involved in sports.

\section{Conclusion}

Our study concluded that smoking reduces aerobic capacity by causing delayed and reduced heart rate recovery among male university smokers. Although, statistically no significant reduction was found in the fatigue index which measures anaerobic capacity. Smoking manifests as an extra-pulmonary manifestation such as increased resting heart rate, decreased aerobic capacity, increased post-exercise heart rate etc. and awareness programmes should be conducted to educate the population especially the young adults about the same.

\section{Abbreviations}

BMI: Body Mass Index, PHR: Pre-heart Rate, HRR: Heart Rate Recovery, PCr: Phosphocreatine, IST: Intermittent Sprint Test

\section{Source of Funding: None}

Conflict of Interest: None

\section{References}

1. Leone A, Landini L, Leone A. What is Tobacco Smoke? Sociocultural Dimensions of the Association with Cardiovascular Risk. Curr Pharm Des. 2010;16(23):2510. [PubMed] [Google Scholar]

2. Saha SP, Bhalla DK, Whayne Jr TF, Gairola C. Cigarette 
smoke and adverse health effects: An overview of research trends and future needs. Int J Angiol. 2007;16(3):77-83. [PubMed] [Google Scholar]

3. Ministry of Health and Family Welfare Government of India [Internet]. National Tobacco Control Programme. Available from: https://ntcp.nhp.gov.in/. Last accessed on $30 / 06 / 2021$.

4. Von Ah D, Ebert S, Ngamvitroj A, Park N, Kang D. Factors Related to Cigarette Smoking Initiation and Use among College Students. Tob Induc Dis. 2005;3(1):27-40. [PubMed] [Google Scholar]

5. Naing NN, Ahmad Z, Musa R, Hamid FR, Ghazali H, Bakar MH. Factors Related to Smoking Habits of Male Adolescents. Tob Induc Dis. 2004;2(3):133-40. [PubMed] [Google Scholar]

6. Mallaina $P$, Lionis $C$, Rol $H$, Imperiali $R$, Burgess $A$, Nixon M, Malvestiti FM. Smoking cessation and the risk of cardiovascular disease outcomes predicted from established risk scores: Results of the Cardiovascular Risk Assessment Among Smokers in Primary Care in Europe (CV-ASPIRE) Study. BMC Public Health. 2013;13:362. [PubMed] [Google Scholar]

7. Yusuf $S$, Hawken S, Ounpuu S, Dans T, Avezum A, Lanas F, McQueen M, Budaj A, Pais P, Varigos J, Lisheng L, Interheart Study Investigators. Effect of potentially modifiable risk factors associated with myocardial infarction in 52 countries (the INTERHEART study): case-control study. Lancet. 2004;364(9438):937-52. [PubMed] [Google Scholar]

8. Iyriboz Y, Powers S, Morrow J, Ayers D, Landry G. Accuracy of pulse oximeters in estimating heart rate at rest and during exercise. Br J Sports Med. 1991;25(3):162-4. [PubMed] [Google Scholar]

9. Indian council of medical research survey on noncommunicable diseases. 2017.https://main.mohfw. gov.in/sites/default/files/Traning\%20Manual\%20 for\%20Community\%20Health\%20Workers\%20on\%20 Reducing\%20Risk\%20Factors\%20of\%20NCDs_1.pdf. Last accessed on 30/06/2021.

10. Shenoy S, Wagle SS, Sandhu JS, Singh HP. Relationship of maximal aerobic capacity with predictors of cardiovascular diseases in North Indian cardiac patients. Heart Asia. 2012;4(1):62-6. [PubMed] [Google Scholar]

11. Johncy SS, Samuel TV. Comparative Study of Aerobic Power in North and South Indians. J Biomed Sci Res. 2010;2(3):155-61.

12. Siddiq M, Dhundasi SA, Aslam M. A study on oxygen independent fitness (anaerobic capacity) in precollegiate boys of Vijayapur, North Karnataka, India. Int J Res Med Sci. 2017;5(5):2062-8.

13. Lee $C L, C h a n g$ WD. The effects of cigarette smoking on aerobic and anaerobic capacity and heart rate variability among female university students. Int J
Womens Health. 2013;5:667-79. [PubMed] [Google Scholar]

14. Mons U, Müezzinler A, Gellert C, Schöttker B, Abnet CC, Bobak M, de Groot L, Freedman ND, Jansen E, Kee F, Kromhout D, Kuulasmaa K, Laatikainen T, O'Doherty MG, Bueno-de-Mesquita B, Orfanos P, Peters A, van der Schouw YT, Wilsgaard T, Wolk A, Trichopoulou A, Boffetta $\mathrm{P}$, Brenner $\mathrm{H}$, CHANCES Consortium. Impact of smoking and smoking cessation on cardiovascular events and mortality among older adults: metaanalysis of individual participant data from prospective cohort studies of the CHANCES consortium. BMJ. 2015;350:h1551. [PubMed] [Google Scholar]

15. Rietbrock N, Kunkel S, Wörner W, Eyer P. Oxygendissociation kinetics in the blood of smokers and non-smokers: interaction between oxygen and carbon monoxide at the hemoglobin molecule. Naunyn Schmiedebergs Arch Pharmacol. 1992;345(1):123-8. [PubMed] [Google Scholar]

16. Hirsch GL, Sue DY, Wasserman K, Robinson TE, Hansen JE. Immediate effects of cigarette smoking on cardiorespiratory responses to exercise. J Appl Physiol. 1985;58(6):1975-81. [PubMed] [Google Scholar]

17. McDonough P, Moffatt RJ. Smoking-induced elevations in blood carboxyhaemoglobin levels. Effect on maximal oxygen uptake. Sports Med. 1999;27(5):275-83. [PubMed] [Google Scholar]

18. Huie MJ, Casazza GA, Horning MA, Brooks GA. Smoking increases conversion of lactate to glucose during submaximal exercise. J Appl Physiol. 1996;80(5):15549. [PubMed] [Google Scholar] 